\title{
Primate imports confusion
}

\section{Washington}

More than a year after a monkey virus related to the deadly Ebola strain infected four US animal handlers and shut down the primate import trade, state and federal health officials are still at a stalemate over regulations governing the importation of laboratory primates.

Despairing of a solution soon, one of the country's largest importers has abandoned New York state, whose stringent regulations are effectively prohibiting primate imports. Charles River Laboratories is moving its primate operations to an existing facility in Houston, Texas, which does not have the strict antibody test requirement demanded in New York. Other importers complain that federal regulators are dragging their heels on evaluating the problem, and that by allowing emergency measures to remain in effect for 16 months, the regulators have cost researchers millions in unnecessary primate expenses.

State and federal regulations have remained essentially unchanged since March last year, when the federal Centers for Disease Control (CDC) and several states imposed new "temporary" quarantine and testing procedures to ensure that imported monkeys are not infected with a filovirus related to the strain that killed hundreds of people in an Ebola outbreak in Zaire in 1976. Since then, researchers have found that the current virus is not Ebola, but another filovirus that is difficult to transmit and does not appear to threaten humans.

Nevertheless, the CDC as well as New York, California and other states have retained their emergency import restrictions. CDC require special airline handling procedures, and a 31-day quarantine coupled with blood titre tests at the beginning and end to ensure that the animals do not have an active infection. New York requires that the monkeys be serotested and quarantined in their country of origin and certified to be entirely free of any signs of filovirus infection.

Leo Grady, chief of the New York Department of Health virology laboratory, says health officials would be willing to lift the state restriction as soon as they see experimental evidence that latent filovirus infections cannot spread to other primates and humans. But such studies are not easy to do and only two US facilities - CDC laboratories in Atlanta and the Army's Medical Research Institute for Infectious Diseases have the required resources.

$\mathrm{CDC}$ has done the experiment, says Kenneth Herrmann, deputy director of the agency's division of viral and rickettsial diseases. Two studies with 16 monkeys and two strains of virus resulted in "not one instance where the virus or viral antigen was found two weeks after infection," he says. "We've proved to our satisfaction that there really is no risk [of transmission] from a seropositive animal that is not ill." But the data will not be

published until fall, he says, and CDC has no plans to lifts its own regulations until the data is out.

This goes down badly with researchers and primate importers, who were hit hardest by the emergency measures last year. After CDC temporarily shut down several of the largest primate importers and all US airlines decided to stop carrying the monkeys, the primate trade came to a virtual halt. Although CDC eventually recertified the importers, the continuing state and federal import restrictions and the forced dependence on non-US air carriers has more than doubled the cost of research primates, says Robert Doolin, director of Charles River Laboratories' national primate operations.

Cynomolgus monkeys that cost between $\$ 300$ and $\$ 400$ in 1989 now cost between $\$ 1,500$ and $\$ 1,600$, in part because transportation and handling costs have tripled.

In a letter of 9 May to CDC chief William Roper, Paul Schilling, director of Charles FOODAND DRUG ADMINISTRATION

\section{Tempest over polio vaccine}

\section{Washington}

DESPITE protests from the US pharmaceutical industry, government regulators are preparing to relax standards for the testing of polio vaccines to allow foreign competition in the $\$ 100$ million US market.

Last month, the Food and Drug Administration (FDA) published new regulations that would for the first time allow the US sale of polio vaccines that have passed the current World Health Organization (WHO) test instead of the usual US test. FDA hopes that some of the non-US companies that now sell WHO-tested vaccines elsewhere in the world will begin to market them in the United States, which would probably lower the price of the vaccine to government health agencies and to the public. On the basis of a five year review of worldwide data, the FDA concluded that both tests are equally effective in screening vaccine batches for safety.

But the one company that now sells the polio vaccine in the United States is fighting the decision. Lederle Laboratories, which has had the US market to itself for more than a decade, says that the FDA decision will force it from the polio vaccine market by putting it in an untenable product liability position. For the past five years, the company has argued that the epidemiological data that FDA uses may be flawed by under-reporting of polio cases and the low potency of some vaccines used outside of the United States.

Now that FDA has rejected those arguments, Lederle is worried that its strategy may have backfired. There are only about five cases of vaccine-induced polio in the United States each year, but, in almost every instance, the victim successfully sues
River's primate breeding operations and president of the Association of Primate Veterinarians, warned that the CDC regulations were costing the research community at least $\$ 12$ million a year.

Schilling estimates that because of the various restrictions, about 20 per cent of the nationwide primate demand last year went unfilled. Before the New York emergency regulations took effect last March, 80 per cent of the 20,000 research primates that were imported into the United States yearly came through John F. Kennedy Airport. Virtually no primates have come through JFK since then, says Grady.

Although researchers are hoping that publication of the CDC data this fall will put an end to the "temporary" nationwide restriction, New York may be an exception. No decision is expected there until a new state health commissioner is appointed to replace David Axelrod, who drove through the rigid regulations last March and has been in a coma for several months with a serious illness.

Christopher Anderson
Lederle. Million-dollar settlements are common. If FDA allows foreign companies to use the WHO test, Lederle would be put in an awkward legal position whenever someone comes down with the disease. If the company has not switched to the WHO test, a plaintiff could reasonably ask why it had not adopted the international standard that FDA had, after all, designated as "referred". If Lederle does use the WHO test, the victim could point out that the company itself had gone to great lengths over the past five years to show that the test may be unsafe.

So, to avoid an automatic court loss every time a vaccination goes awry, Lederle may have to use both tests, at more than twice the cost of the WHO test alone. That, the company argues, could put it out of the polio vaccine business because its competitors, using only one test, would have a cost advantage.

Lederle has at least one powerful friend in the matter. Late last month, Representative John Dingell (Democrat, Michigan), the chairman of the House Energy and Commerce Committee, warned FDA commissioner David Kessler that he would not stand for regulations that disadvantage US industry. "I am strongly opposed to any situation where regulation promulgated by a US regulatory agency put a US company which uses US standards at risk," Dingell wrote in a letter dated 21 May.

FDA officials have until the end of this month to decide how to respond. But unless the agency reverses its decision, WHOtested polio vaccines will become legal in the United States on 21 June, and Lederle lawyers will have to begin preparing for the worst. 